\title{
AVALIAÇÃO DA MISTURA DE SUCO DE UVA E SUSPENSÃO DE SACCHAROMYCES CEREVISIAE EM MICROCANAIS COM E SEM MICROMISTURADORES.
}

\author{
Vinícius de O. Concentino*, Adriano G.P. Silva, Harrson S. Santana, Osvaldir P. Taranto.
}

\section{Resumo}

O escoamento de suco de uva e da suspensão Saccharomyces Cerevisiae foi simulado computacionalmente em microcanais com e sem obstruções em números de Reynolds (Re) variando de 0,01-100. Elevados índices de mistura $(I M \approx 1)$ foram obtidos em baixos $\operatorname{Re}(0,01,0,1$ e 1$)$ para todas as geometrias e em $\operatorname{Re}=100$ para o microcanal com chicanas. O aumento da velocidade de escoamento (aumento de Re) gerou inicialmente uma diminuição em todos os índices de mistura. Um aumento contínuo de velocidade restabeleceu o elevado IM (IM $\approx 1$ ) para o escoamento em microcanal com chicanas, sendo este o melhor canal de mistura entre os investigados.

\section{Palavras-chave:}

Micromisturadores, vinho, Saccharomyces Cerevisiae.

\section{Introdução}

Processos fermentativos, como é o caso da produção de vinho, em microdispositivos, vêm sendo estudados ao longo dos anos. Dispositivos microfluídicos possuem elevadas relações superfície-volume o que os tornam extremamente vantajosos, sendo bastante utilizados nas indústrias químicas e de alimentos. Em ambientes microfluídicos as espécies químicas são misturadas principalmente pela difusão molecular, sendo um processo naturalmente lento. Logo, são necessárias ferramentas que melhorem a mistura de componentes, os micromisturadores, favorecendo maiores rendimentos e produtividade (Lee et al, 2011). Assim, o objetivo do trabalho é investigar maiores potenciais de mistura entre - suco de uva e de leveduras em suspensão em microcanais com e sem micromisturadores.

Resultados e Discussão
As simulações foram realizadas através de
fluidodinâmica computacional (Ansys CFX 17.2) em
microcanais de seção retangular de 1500x200 $\mu$, para
três tipos de misturadores: sem obstruções, com
obstruções circulares e com obstruções do tipo chicanas
(Figura 1). Foram fornecidos ao software dados de
viscosidade dinâmica, massa específica e condutividade
térmica de ambas as fases fluidas a $25^{\circ} \mathrm{C}$.

(a)

(b)

$\frac{180808080808080808080808080808}{\text { (c) }}$

Figura 1. Microcanais: a) obstruções do tipo chicana, b) obstruções circulares, c) sem obstruções.

O índice de mistura (IM) foi calculado de acordo com Santana et al. (2017), e seu comportamento está apresentado na Figura 2. Em baixo valores de $\operatorname{Re}(0,01$, 0,1 e 1) verificou-se elevados IM para as três geometrias $(\mathrm{IM} \approx 1)$, neste valor de $\mathrm{Re}$ a transferência de massa ocorre principalmente por difusão molecular, sendo um processo naturalmente lento. Com o aumento da velocidade de escoamento, aumento de Re, menor é o tempo que as moléculas possuem para se deslocar até o lado oposto do canal, diminuindo assim a eficiência de mistura.

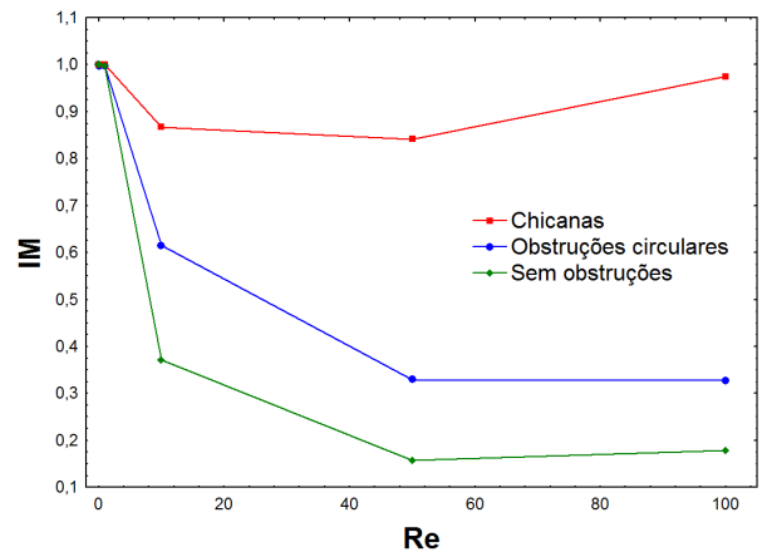

Figura 2. Índice de mistura pelo Reynolds.

Um aumento contínuo do número de Re gera uma fase de crescimento no IM para o microcanal com obstruções do tipo chicanas, até atingir novamente o valor de $I M \approx 1$. Este resultado é justificado devido ao processo de advecção que passa a superar a contribuição difusiva, ocasionando uma melhora na mistura.

\section{Conclusões}

$\mathrm{O}$ IM atingiu maiores valores (IM $\approx 1)$ em Re iguais a 0,01 , 0,1 e 1 para os três tipos de microcanais. $O$ aumento de Re proporcionou inicialmente uma queda nos IM, seguido de um aumento para o microcanal com chicanas. A presença de obstruções do tipo chicanas contribuiu para a obtenção dos maiores IM em toda a faixa de $\mathrm{Re}$ utilizada, sendo este o melhor canal para mistura.

\section{Agradecimentos}

Os autores agradecem o suporte financeiro do CNPq.

Lee C.Y., Chang C.L., Wang Y.N., Fu L.M., Microfluidic Mixing: A Review, Int. J. Mol. Sci. 12. 3263-3287. 2011.

Santana HS, Tortola D.S, Silva JR. JL, Taranto OP, Biodiesel synthesis in micromixer with static elements. Energ. Conv. Manage, v. 141, p. 28-39, 2017. 